\title{
Hubungan Gangguan Tidur dan Prestasi Akademik pada Siswa Kelas III, IV, dan V Sekolah Dasar di Jatinangor, Sumedang, Jawa Barat
}

\author{
Inge Yasmien, Rodman Tarigan, Lynna Lidyana \\ Departemen Ilmu Kesehatan Anak Fakultas Kedokteran Universitas Padjadjaran/ RS Hasan Sadikin, Bandung
}

\begin{abstract}
Latar belakang. Dampak gangguan tidur yang melibatkan beberapa aspek dan angka kejadian gangguan tidur yang cukup tinggi masih kurang mendapatkan perhatian dari orang tua anak maupun tenaga medis. Gangguan tidur dikaitkan dengan fungsi kognitif dan keberhasilan akademik anak.

Tujuan. Menggambarkan prevalensi gangguan tidur pada anak usia sekolah dasar serta mengetahui pengaruh gangguan tidur dan faktor sosiodemografi terhadap prestasi akademik di kawasan Jatinangor.

Metode. Desain penelitian potong lintang dilakukan di tiga sekolah dasar kelas 3, 4, dan 5 di kawasan Jatinangor pada bulan AgustusSeptember 2019. Orang tua mengisi lembar kuesioner skala gangguan tidur untuk anak (SDSC) dan kuesioner karakteristik subjek. Prestasi akademik dinilai dengan membandingkan nilai rata-rata individu terhadap nilai rata-rata satu kelas.

Hasil. Subjek yang dapat dianalisis berjumlah 101 anak. Sebanyak 65,3\% subjek mengalami gangguan tidur dan 49,5\% subjek memiliki nilai di bawah nilai rata-rata kelas. Hasil analisis menunjukkan adanya hubungan berarti antara gangguan tidur dengan hasil prestasi akademik anak $(\mathrm{p}=0,044)$. Terdapat juga hubungan yang berarti antara pendidikan orang tua $(\mathrm{p}=0,042)$ dan jenis kelamin ( $\mathrm{p}=0,037)$ dengan hasil prestasi akademik anak.

Kesimpulan. Penelitian menunjukkan adanya hubungan bermakna antara gangguan tidur dan prestasi akademik. Faktor sosiodemograsi yang berpengaruh terhadap prestasi akademik adalah jenis kelamin dan pendidikan orang tua anak. Sari Pediatri 2020;21(5):310-16
\end{abstract}

Kata kunci: prestasi akademik, gangguan tidur, siswa sekolah dasar, sekolah dasar

\section{Correlation between Sleep Disorders and Academic Performance among Primary Schools Students Grade III, IV, and V in Jatinangor, Sumedang, West Java}

Inge Yasmien, Rodman Tarigan, Lynna Lidyana

Background. The impact of sleep disorders involving several aspects and a high incidence rate of sleep disorders still receive less attention from the parents and the medical personnel. Sleep disorders may influence cognitive function and academic performance of children. Objective. To know the prevalence of sleep disorders in elementary school age children and to find the effects of sleep disorders and sociodemographic factors on academic achievement in the Jatinangor.

Methods. The cross-sectional study design was carried out in three elementary schools grade 3, 4, and 5 in the Jatinangor on AugustSeptember 2019. Parents were instructed to complete the sleep disturbance scale for children and subject characteristics questionnaire. Academic achievement obtained by comparing the average score of an individual and the average score of each class.

Result. 101 subjects can be analyzed. As many as $65.3 \%$ of subjects had sleep problems and $49.5 \%$ of subjects had scored lower than the class average. The results showed a correlation between sleep disorder and academic achievement $(\mathrm{p}=0.044)$. There was correlation between gender $(\mathrm{p}=0.037)$ and parental education $(\mathrm{p}=0.042)$ with academic achievement.

Conclusion. Research showed a correlation between sleep disorder and academic achievement. Sociodemographic factors that influence academic achievement were sex and parental education. Sari Pediatri 2020;21(5):310-16

Keywords: academic performance, sleep disturbance, elementary school students, primary school

Alamat korespondensi: Rodman Tarigan. Departemen Ilmu Kesehatan Anak Fakultas Kedokteran UNPAD, Jl. Pasteur No. 28, Sukajadi, Bandung 40161. Email: rodmantarigan@yahoo.co.id 
Inge Yasmien dkk: Hubungan gangguan tidur dan prestasi akademik pada siswa kelas III, IV, dan V sekolah dasar

T

idur merupakan salah satu proses fisiologis yang menjadi kebutuhan dasar yang sangat penting untuk setiap individu.

Kebutuhan tidur seseorang berbeda-beda dan dipengaruhi oleh beberapa faktor, misalnya faktor usia. Ketika kebutuhan tidur tidak dapat terpenuhi secara kuantitas maupun kualitas maka akan mengakibatkan adanya suatu masalah gangguan tidur. ${ }^{1}$ Gangguan tidur dapat menyebabkan kelelahan, penurunan sistem kekebalan tubuh dan konsentrasi dalam berpikir. Selain itu, gangguan tidur juga dapat memengaruhi pengaturan emosi, perhatian, proses pembelajaran, daya ingat, dan keberhasilan akademis pada seorang anak. ${ }^{2}$ Gangguan rentang waktu tidur pada anak juga dikaitkan dengan adanya masalah fungsi kognitif dan gangguan pemusatan perhatian anak. $^{3}$

Beberapa jurnal menyebutkan bahwa gangguan tidur sering terjadi pada anak. Sebuah jurnal penelitian yang dilakukan di Brazil menyimpulkan bahwa prevalensi gangguan tidur pada rentang usia 0-19 tahun menunjukkan angka 25,5\%. Jumlah penelitian mengenai gangguan tidur di Indonesia masih terbatas. Suatu penelitian yang dilakukan pada anak sekolah usia 12-15 tahun di Jakarta Timur menyimpulkan bahwa $62,9 \%$ anak mengalami kejadian ketidaknormalan pada saat tidur dan model gangguan paling banyak adalah perpindahan fase bangun dan tidur. Jumlah kejadian tersebut terbilang cukup tinggi.

Walaupun demikian, dampak gangguan tidur yang melibatkan beberapa aspek dan angka kejadian gangguan tidur yang cukup tinggi tersebut masih kurang mendapatkan perhatian dari orang tua anak. ${ }^{6}$ Di samping itu, beberapa tenaga kesehatan juga jarang melakukan deteksi gangguan tidur pada anak secara rutin. Penelitian ini ber tujuan untuk menggambarkan angka kejadian gangguan tidur yang dialami anak usia sekolah dasar dengan menggunakan kuesioner skala gangguan tidur untuk anak (SDSC) serta mengetahui pengaruh gangguan tidur dan faktor sosiodemografi terhadap prestasi akademik di kawasan Jatinangor.

\section{Metode}

Desain penelitian potong lintang (cross sectional) dilakukan di tiga sekolah dasar kawasan Jatinangor pada bulan Agustus-September 2019. Subjek penelitian adalah siswa kelas 3, 4, dan 5 di SDN Jatinangor,
SDN Neglasari, dan SD Inklusi Azaddy Al Ghozzaly. Kriteria inklusi adalah anak merupakan siswa kelas 3, 4, dan 5 sekolah dasar di kecamatan Jatinangor; pengisian kuesioner dilakukan oleh orang tua atau wali dari siswa; dan anak memiliki nilai raport dalam satu tahun terakhir. Subjek dipilih melalui teknik total klaster sampling. Orang tua atau wali anak menyetujui lembar informed consent, mengisi lembar kuesioner sleep disorders scale for children (SDSC) bersama anak yang berisi dua puluh enam pertanyaan, dan lembar kuesioner karakteristik subjek. Instrumen SDSC tersebut sudah divalidasi dalam bentuk bahasa indonesia sebagai alat deteksi dini gangguan tidur. ${ }^{5,8}$ Subjek termasuk drop out jika tidak mengembalikan lembar kuesioner dan diekslusi apabila tidak mengisi lembar kuesioner SDSC dengan lengkap atau tidak memiliki laporan hasil belajar selama satu tahun terakhir.

Karakteristik subjek yang diikutsertakan dalam penelitan, meliputi jenis kelamin, tingkat kelas, usia, penghasilan orang tua, pendidikan terakhir orang tua, kebiasaan tidur siang, kegiatan ekstrakulikuler, adanya teman tidur, dan adanya ponsel atau komputer atau televisi pribadi. Subjek didiagnosis dengan gangguan tidur apabila hasil total skor pada kueioner SDSC berada di atas nilai cut of point, yaitu 39 yang memiliki sensitivitas $89 \%$ dan spesifisitas $74 \%{ }^{3}$ Prestasi akademik dinilai dengan membandingkan nilai rata-rata dari hasil prestasi belajar individu terhadap nilai rata-rata dari hasil belajar di dalam satu kelas yang sama. Pengolahan dan analisis data dilakukan dengan menggunakan aplikasi IBM SPSS Statistics 20. Analisis yang dilakukan adalah analisis bivariat tidak berpasangan dengan uji chi-square. Hubungan bermakna secara statistik akan didapatkan apabila nilai $\mathrm{p} \leq 0,05$. Penelitian telah mendapatkan izin penelitian dari Komite Etik Penilitian Universitas Padjadjaran dan Dinas Pendidikan Kabupaten Sumedang.

\section{Hasil}

Jumlah siswa yang menerima lembar kuesiner di kelas 3, 4, dan 5 dari SDN Jatinangor, SDN Neglasari, serta SD Inklusi Al Ghazali berjumlah 145 anak. Sebanyak 121 siswa mengembalikan kuesioner dengan lembar informed consent yang sudah ditandatangani, 24 siswa drop out karena tidak mengembalikan lembar kuesioner dan informed consent, dan 20 siswa dieksklusi karena 
Inge Yasmien dkk: Hubungan gangguan tidur dan prestasi akademik pada siswa kelas III, IV, dan V sekolah dasar

Tabel 1 Gambaran dari karakteristik subjek

\begin{tabular}{|c|c|c|}
\hline Variabel & $\begin{array}{l}\text { Jumlah } \\
(\mathrm{n})\end{array}$ & $\begin{array}{c}\text { Persentase } \\
\quad(\%)\end{array}$ \\
\hline \multicolumn{3}{|l|}{ Jenis kelamin } \\
\hline Perempuan & 52 & 51,5 \\
\hline Laki-laki & 49 & 48,5 \\
\hline \multicolumn{3}{|l|}{ Usia } \\
\hline 7 & 3 & 3 \\
\hline 8 & 21 & 20,8 \\
\hline 9 & 32 & 31,7 \\
\hline 10 & 32 & 31,7 \\
\hline 11 & 13 & 12,9 \\
\hline \multicolumn{3}{|l|}{ Tingkat kelas } \\
\hline 3 & 29 & 28.7 \\
\hline 4 & 37 & 36.6 \\
\hline 5 & 35 & 34.7 \\
\hline \multicolumn{3}{|l|}{ Pendapatan orang tua } \\
\hline \multicolumn{3}{|l|}{ Rendah } \\
\hline $\begin{array}{l}\text { Sedang } \\
(1.500 .000-2.500 .000)\end{array}$ & 33 & 32.7 \\
\hline \multicolumn{2}{|l|}{ Tinggi } & 12.9 \\
\hline \multicolumn{3}{|l|}{ Sangat tinggi } \\
\hline \multicolumn{3}{|l|}{ Pendidikan orang tua } \\
\hline Rendah & 39 & 38.6 \\
\hline Menengah & 51 & 50.5 \\
\hline Tinggi & 11 & 10.9 \\
\hline \multicolumn{3}{|l|}{ Kebiasaan tidur siang } \\
\hline $\mathrm{Ya}$ & 39 & 38.6 \\
\hline Tidak & 62 & 61,4 \\
\hline \multicolumn{3}{|l|}{ Kegiatan ekstrakurikuler } \\
\hline Ya & 38 & 37,6 \\
\hline Tidak & 63 & 62,4 \\
\hline \multicolumn{3}{|c|}{$\begin{array}{l}\text { Adanya ponsel pribadi, TV atau } \\
\text { komputer di kamar }\end{array}$} \\
\hline $\mathrm{Ya}$ & 45 & 44,6 \\
\hline Tidak & 56 & 55,4 \\
\hline \multicolumn{3}{|l|}{ Adanya teman tidur } \\
\hline Ya & 78 & 77,2 \\
\hline Tidak & 23 & 22,8 \\
\hline
\end{tabular}

tidak mengisi kuesioner SDSC dengan lengkap. Dengan demikian, jumlah subjek yang dapat dianalisis berjumlah 101 anak atau sekitar $69.66 \%$ dari total subjek.

Hasil pengolahan data menunjukkan sebagian besar subjek berjenis kelamin perempuan, berusia
Tabel 2. Gambaran subjek berdasarkan gangguan tidur dan hasil prestasi akademik

\begin{tabular}{lcc}
\hline Variabel & $\begin{array}{c}\text { Jumlah } \\
(\mathrm{n})\end{array}$ & $\begin{array}{c}\text { Persentase } \\
(\%)\end{array}$ \\
\hline Gangguan tidur & & \\
$\quad$ Tidak mengalami gangguan tidur & 35 & 34,7 \\
$\quad$ Mengalami gangguan tidur & 66 & 65,3 \\
Prestasi akademik & & \\
$\quad$ Baik & 51 & 50,5 \\
$\quad$ Kurang baik & 50 & 49,5 \\
\hline
\end{tabular}

9-10 tahun, kelas 4 sekolah dasar, pendapatan orang tua rendah, dan pendidikan orang tua menengah. Penggolongan pendapatan orang tua tersebut berdasarkan penggolongan Badan Pusat Statistik (BPS). Sebagian besar subjek juga tidak memiliki kebiasaan tidur siang, tidak memiliki kegiatan ekstrakurikuler, tidak memiliki ponsel pribadi atau televisi atau komputer di dalam kamar, dan memiliki teman tidur dalam satu kamar. Untuk sebaran karakteristik subjek tertera pada Tabel 1. Sebanyak $65,3 \%$ subjek mengalami gangguan tidur dan $49,5 \%$ subjek memiliki hasil prestasi akademik di bawah nilai rata-rata kelas. Prevalensi gangguan tidur dan sebaran hasil prestasi akademik tertera pada Tabel 2. Setelah dilakukan analisis bivariat tidak berpasangan dengan uji chi-square didapatkan adanya hubungan berarti antara gangguan tidur dengan hasil prestasi akademik. Selain itu, terdapat juga hubungan bermakna antara pendidikan pada orang tua dan jenis kelamin anak dengan hasil prestasi belajar pada anak. Faktor lain, seperti usia, tingkat kelas, pendapatan orang tua, kebiasaan tidur siang, adanya kegiatan ekstrakurikuler, adanya ponsel pribadi atau televisi atau komputer di kamar, dan adanya teman tidur tidak menunjukkan adanya hubungan yang bermakna dengan hasil prestasi akademik anak. Hasil analisis hubungan antara karakteristik subjek dan hasil prestasi akademik pada siswa SDN Jatinangor, SDN Neglasari, serta SD Inklusi Al Ghazali tertera pada Tabel 3.

\section{Pembahasan}

Penelitian gangguan tidur di Indonesia masih sangat terbatas jumlahnya, termasuk untuk wilayah Bandung dan sekitarnya. Hasil penelitian pada siswa sekolah dasar usia 7-11 tahun di Jatinangor menunjukkan adanya kejadian gangguan tidur sebesar 65,3\%. Hasil tersebut 
Inge Yasmien dkk: Hubungan gangguan tidur dan prestasi akademik pada siswa kelas III, IV, dan V sekolah dasar

Tabel 3 Hubungan karakteristik subjek dengan hasil prestasi akademik

\begin{tabular}{|c|c|c|c|}
\hline \multirow[t]{3}{*}{ Variabel } & \multicolumn{3}{|c|}{ Hasil prestasi akademik } \\
\hline & \multicolumn{2}{|c|}{ Nilai rata-rata } & \multirow[t]{2}{*}{$\mathrm{p}$} \\
\hline & Di bawah rata-rata & Di atas rata-rata & \\
\hline \multicolumn{4}{|l|}{ Gangguan tidur } \\
\hline Tidak mengalami gangguan tidur & 12 & 23 & 0,044 \\
\hline Mengalami gangguan tidur & 38 & 28 & \\
\hline \multicolumn{4}{|l|}{ Jenis kelamin } \\
\hline Perempuan & 20 & 32 & 0,037 \\
\hline Laki-laki & 30 & 19 & \\
\hline \multicolumn{4}{|l|}{ Usia } \\
\hline 7 & 2 & 1 & 0,856 \\
\hline 8 & 12 & 9 & \\
\hline 9 & 14 & 18 & \\
\hline 10 & 16 & 16 & \\
\hline 11 & 6 & 7 & \\
\hline \multicolumn{4}{|l|}{ Tingkat kelas } \\
\hline 3 & 16 & 13 & 0,751 \\
\hline 4 & 17 & 20 & \\
\hline 5 & 17 & 18 & \\
\hline Pendapatan orang tua & & & 0,054 \\
\hline Rendah $(<1.500 .000)$ & 21 & 18 & \\
\hline Sedang (1.500.000-2.500.000) & 11 & 22 & \\
\hline Tinggi (2.500.000-3.500.000) & 10 & 3 & \\
\hline Sangat tinggi $(>3.500 .000)$ & 8 & 8 & \\
\hline \multicolumn{4}{|l|}{ Pendidikan orang tua } \\
\hline Rendah & 25 & 14 & 0,042 \\
\hline Menengah & 22 & 29 & \\
\hline Tinggi & 3 & 8 & \\
\hline \multicolumn{4}{|l|}{ Kebiasaan tidur siang } \\
\hline $\mathrm{Ya}$ & 19 & 20 & 1,000 \\
\hline Tidak & 31 & 31 & \\
\hline \multicolumn{4}{|l|}{ Kegiatan ekstrakurikuler } \\
\hline Ya & 16 & 22 & 0,342 \\
\hline Tidak & 34 & 29 & \\
\hline \multicolumn{4}{|c|}{ Adanya ponsel pribadi, TV atau komputer di kamar } \\
\hline $\mathrm{Ya}$ & 24 & 21 & 0,624 \\
\hline Tidak & 26 & 30 & \\
\hline \multicolumn{4}{|l|}{ Adanya teman tidur } \\
\hline Ya & 37 & 41 & 0,597 \\
\hline Tidak & 13 & 10 & \\
\hline
\end{tabular}

lebih besar dibandingkan dengan prevalensi gangguan tidur pada anak sekolah dasar di SDN Pondok Cina Depok usia 7-12 (44,8\%) dan prevalensi gangguan tidur pada sekolah lanjutan pertama di Jakarta Timur $(62,9 \%)^{2,8}$ Namun, prevalensi tersebut lebih rendah apabila dibandingkan dengan penelitian pada anak usia 6,5-15,3 tahun yang menunjukkan angka kejadian $73,4 \% .{ }^{9}$ Keempat penelitian tersebut menggunakan kuesioner SDSC sebagai instrumen diagnosis gangguan tidur dengan sebaran usia yang berbeda-beda. 
Hasil analisis hubungan karakteristik sosiodemografi subjek dengan prestasi akademik menunjukkan adanya hubungan bermakna antara jenis kelamin dan pendidikan orang tua anak. Hasil penelitian kami ini sejalan dengan penelitian Atamimi ${ }^{10}$ yang melaporkan adanya keterkaitan antara perbedaan jenis kelamin dengan motivasi akademik, kapasitas akademik, dan keberhasilan akademik. Demikian pula dengan laporan penelitian Auliyanti dkk ${ }^{11}$ bahwa anak dengan jenis kelamin laki-laki berpeluang lebih tinggi untuk mendapatkan prestasi akademik yang rendah. Namun, sebelum dilakukan penelitian-penelitian tersebut, Ebenuwa $^{12}$ telah melaporkan bahwa jenis kelamin bukanlah faktor penyebab yang berakna terhadap prestasi akademik. Ali $\mathrm{dkk}^{13}$ juga melaporkan bahwa gender tidak menunjukkan adanya perbedaan dalam prestasi akademik. Fischer $\mathrm{dkk}^{14}$ melaporkan bahwa prestasi pada perempuan lebih unggul karena tingkat motivasi diri yang lebih tinggi, kemampuan mengontrol diri yang lebih baik, dan memiliki kebanggaan akan produktivitas mereka.

Penelitian kami sesuai dengan Farooq $\mathrm{dkk}^{15}$ yang melaporkan adanya keterkaitan yang bermakna antara pendidikan orang tua terhadap keseluruhan prestasi akademik anak, prestasi bidang matematika, dan bahasa Inggris. Hubungan yang bermakna antara latar belakang pendidikan pada orang tua dan prestasi belajar anak juga disebutkan dalam penelitian Bjorkund dan Salvanes. ${ }^{16}$ Sharma dan Misrha ${ }^{17}$ melaporkan tingkat pendidikan orang tua akan memberikan lingkungan positif kepada anak untuk mendapatkan prestasi akademik yang baik. Hal tersebut dikaitkan kepada kesadaran orang tua akan prestasi anaknya sehingga akan memberikan fasilitas dan pembinaan yang lebih baik. Namun, hasil penelitian Auliyanti $\mathrm{dkk}^{11}$ melaporkan tidak terdapat korelasi yang bermakna antara pendidikan terakhir pada orang tua dan prestasi akademik anak.

Penelitian ini melaporkan tidak terdapat keterkaitan antara usia anak dengan prestasi akademik. Hasil tersebut sejalan dengan Jayanthi $\mathrm{dkk}^{18}$ yang memberikan laporan bahwa tidak terdapat keterkaitan yang berarti antara usia dan prestasi akademik. Namun, berbeda dengan Ali $\mathrm{dkk}^{13}$ yang melaporkan terdapat hubungan korelatsi negatif antara usia dengan prestasi akademik, semakin bertambah usia maka prestasi akademik cenderung akan menurun. Kemungkinan disebabkan karena siswa dengan umur yang lebih muda akan lebih berkonsentrasi dalam bidang akademik dan lebih sedikit mendapatkan gangguan sehingga dapat mengimbangi prestasi akademiknya. ${ }^{19}$ Penelitian sejalan dengan Morrissey $\mathrm{dkk}^{20}$ yang melaporkan bahwa tidak ada korelasi bermakna antara ekonomi keluarga yang rendah dengan prestasi akademik. Berbeda dengan hasil penelitian yang melaporkan bahwa tingginya perekonomian keluarga dapat meningkatkan kesempatan anak mendapatkan pendidikan yang lebih baik. ${ }^{2,11} \mathrm{Lam}^{21}$ juga melaporkan bahwa anak dengan sosio-ekonomi rendah akan mendapatkan hasil akademik yang lebih buruk dan memiliki peluang lebih tinggi untuk berhenti sekolah. Kemungkinan penyebabnya adalah pola asuh, harapan, dan pengaruh strategi orang tua dalam mengatasi tekanan.

Tidak terdapat hubungan antara kebiasaan tidur siang dengan prestasi akademik. Pernyataan ini didukung oleh Lovato $\mathrm{dkk}^{22}$ yang melaporkan bahwa anak yang tidur siang mengalami gangguan konsetrasi, gangguan dalam mengorganisasi pikiran, dan gangguan motivasi. Namun, Brooks dan Lack ${ }^{23}$ melaporkan bahwa tidur siang selama sepuluh menit adalah durasi tidur siang yang paling efektif yang dapat meningkatkan semangat dan prestasi akademik, sedangkan tidur siang selama tiga puluh menit akan menghasilkan periode gangguan kesadaran dan performa sesaat setelah bangun tidur. Tidak terdapat hubungan antara adanya ponsel pribadi, komputer atau televisi di kamar dengan prestasi akademik. Hasil tersebut sejalan dengan Auliyanti dkk ${ }^{11}$ yang melaporkan tidak ada hubungan bermakna antara prestasi akademik dengan keberadaan komputer atau televisi di dalam kamar. Berbeda dengan Anatsui dan Adekanye ${ }^{24}$ yang melaporkan bahwa menonton televisi akan menyebabkan potensi akademik anak menjadi kurang berkembang. Menonton televisi terlalu lama akan membuat pikiran anak menjadi tidak berkembang seperti sebagaimana mestinya. Penelitian juga berbeda dengan Kibona dan Myaga ${ }^{25}$ yang melaporkan adanya korelasi negatif antara ponsel genggam dengan prestasi akademik. Hal tersebut dipengaruhi oleh penggunaan ponsel genggam yang lebih sering digunakan untuk sarana hiburan daripada sarana untuk pembelajaran. ${ }^{26}$ Hasil penelitian kami melaporkan bahwa tidak terdapat keterkaitan antara kegiatan ekstrakurikuler dan adanya teman tidur dengan prestasi akademik. Berbeda dengan Jayanthi $\mathrm{dkk}^{18}$ yang melaporkan bahwa kegiatan ekstrakurikuler dapat meningkatkan prestasi akademik siswa.

Terdapat hubungan antara gangguan tidur dengan prestasi akademik pada hasil nilai rata-rata anak. Hasil 
Inge Yasmien dkk: Hubungan gangguan tidur dan prestasi akademik pada siswa kelas III, IV, dan V sekolah dasar

tersebut didukung oleh penelitian Indahwati $\mathrm{dkk}^{2}$ yang melaporkan adanya hubungan gangguan tidur dengan nilai rata-rata dan nilai matematika anak. Auliyanti $\mathrm{dkk}^{11}$ juga membawa dukungan positif terhadap hasil penelitian ini dengan melaporkan bahwa anak dengan gangguan tidur akan cenderung memiliki capaian hasil prestasi yang lebih rendah. Mekanisme hubungan antara gangguan tidur dan prestasi akademik belum diketahui secara pasti, tetapi kemungkinan terjadi karena gangguan tidur dapat memengaruhi kapasitas memori menjadi lebih rendah. ${ }^{27}$ Masalah tidur juga dapat menurunkan sistem sensori, motoris, memori, gangguan kognitif, dan perubahan hormon tubuh. ${ }^{28}$

Penelitian ini belum pernah dilakukan di kawasan Jatinangor. Keterbatasan penelitian kami adalah subjek belum bisa menggambarkan keadaan gangguan tidur pada anak secara luas di daerah Jawa Barat, apalagi untuk wilayah Indonesia karena penelitian hanya terbatas di kawasan Jatinangor; tidak melibatkan seluruh siswa di SDN Jatinangor, SDN Neglasari, dan SD Inklusi Al Ghazali karena hanya meliputi beberapa kelas saja dan ada siswa yang tidak mengembalikan kuesioner atau tidak mengisi kuesioner dengan lengkap; ada beberapa faktor yang memengaruhi prestasi akademik anak yang tidak dimasukkan kedalam penelitian ini; dan jawaban kuesioner merupakan penilaian orang tua terhadap keadaan anaknya karena kita tidak dapat mengetahui keadaan anak secara langsung.

\section{Kesimpulan}

Prevalensi gangguan tidur SDN Jatinangor, SDN Neglasari, dan SD Inklusi Al Ghazali adalah 65,3\%. Faktor sosiodemografi yang berpengaruh terhadap prestasi akademik adalah jenis kelamin dan pendidikan orang tua anak. Penelitian juga menunjukkan adanya hubungan bermakna antara gangguan tidur dan prestasi akademik.

Penelitian kami dapat menjadi dasar untuk pengembangan penelitian lebih lanjut dan dapat dijadikan dorongan untuk tindakan promotif maupun preventif untuk menghindari dampak negatif dari gangguan tidur, terutama pada anak-anak sebagai penerus bangsa. Saran untuk penelitian selanjutnya agar dapat menggambarkan gangguan tidur di Indonesia secara representatif dengan jumlah sampel yang memadai sehingga hasil yang didapatkan akan lebih bermakna.

\section{Ucapan terima kasih}

Penelitian yang saya mulai tidak akan dapat diselesaikan apabila dilakukan tanpa adanya bantuan dari banyak pihak terkait. Oleh karena itu, pada kesempatan kali ini peneliti ingin menyampaikan rasa terima kasih kepada: Kurnia Wahyudi, dr., M.Sc selaku dosen statistik yang telah membantu dalam proses pengerjaan penelitian ini. Begitu juga kepada guru, orang tua atau wali siswa, dan siswa kelas 3, 4, dan 5 di SDN Jatinangor, SDN Neglasari, dan SD Inklusi Azaddy Al Ghozzaly yang telah membantu dalam proses pengumpulan data.

\section{Daftar pustaka}

1. Hirshkowitz M, Whiton K, Albert SM, dkk. National Sleep Foundation's updated sleep duration recommendations: final report. Sleep Health 2015;1:233-43.

2. Indahwati N, Sekartini R. Hubungan antara Prestasi Belajar pada Anak dengan Gangguan Tidur di SDN 03 Pondok Cina Depok. Sari Pediatri 2016;18:175-81.

3. Gruber R, Michaels S, Bergmame L, dkk. Short sleep duration is associated with teacher-reported inattention and cognitive problems in healthy school-aged children. Nature and science of sleep. 2012;4:33-40.

4. de Almeida GMF, Nunes ML. Sleep characteristics in Brazilian children and adolescents: a population-based study. Sleep Medicine: X. 2019;1:100007.

5. Natalita C, Sekartini R, Poesponegoro H. Skala gangguan tidur untuk anak (SDSC) sebagai Instrumen skrining gangguan tidur pada anak sekolah lanjutan tingkat pertama. Sari Pediatri 2011;12:365-72.

6. Sekartini R, Adi N. Gangguan tidur pada anak usia bawah tiga tahun di lima kota di Indonesia. Sari Pediatri 2006;7:188-93.

7. Senthilvel E, Auckley D, Dasarathy J. Evaluation of sleep disorders in the primary care setting: history taking compared to questionnaires. JCSM 2011;7:41-8.

8. Haryono A, Rindiarti A, Arianti A, dkk. Prevalensi gangguan tidur pada remaja usia 12-15 tahun di sekolah lanjutan tingkat pertama. Sari Pediatri 2009;11:149-54.

9. Bruni O, Ottaviano S, Guidetti V, dkk. The sleep disturbance scale for children (SDSC). Construction and validation of an instrument to evaluate sleep disturbances in childhood and adolescence. J Sleep Res1996;5:251-61.

10. Atamimi N. Perbedaan peran jenis kelamin, skala akademik, dan peran aktif berorganisasi dengan prestasi akademik. Jurnal Cakrawala Pendidikan 2014;33:236-44.

11. Auliyanti F, Sekartini R, Mangunatmadja I. Academic 
Inge Yasmien dkk: Hubungan gangguan tidur dan prestasi akademik pada siswa kelas III, IV, dan V sekolah dasar

achievement of junior high school students with sleep disorders. Paediatrica Indones 2016;55:50.

12. Ebenuwa-Okoh EE. Influence of Age, Financial Status, and Gender on Academic Performance among Undergraduates. J Psychol 2010;1:99-103.

13. Ali S, Haider Z, Munir F, Khan H, Ahmed A. Factors Contributing to the Students Academic Performance: A Case Study of Islamia University Sub-Campus. Am J Educ Res 2013;1:283-9.

14. Fischer F, Schult J, Hell B. Sex differences in secondary school success: Why female students perform better. Eur J Psychol Educ 2013;28:529-43.

15. Farooq M, Chaudhry AH, Shafiq M, Berhanu G. Factors affecting students' quality of academic performance: A case of secondary school level. J Quality Technology Management 2011;7:01-14.

16. Björklund A, Salvanes KG. Chapter 3 - Education and family background: mechanisms and policies. Dalam: Hanushek EA, Machin S, Woessmann L, penyunting. handbook of the economics of education. Edisi ke- 3. North Holland: Elsevier; 2011.h.201-47.

17. Sharma G, Mishra S. Acedemic Performance in Relation to Parents education, Institution and Sex. J Psychos Res 2014;9:173-86.

18. Jayanthi S, Balakrishnan S, Lim A, Latiff N, Nasirudeen AMA. Factors Contributing to Academic Performance of Students in a Tertiary Institution in Singapore. American J Edu Res 2014;2:752-8.

19. Nam K. Until when does the effect of age on academic achievement persist? evidence from Korean data. Economics Edu Rev. 2014;40:106-22.

20. Morrissey T, Hutchison L, Winsler A. Family income, school attendance, and academic achievement in elementary school. Dev Psychol 2014;50:741-53.

21. Lam G. A theoretical framework of the relation between socioeconomic status and academic achievement of students. Education 2014;134:326-31.

22. Lovato N, Lack L, Wright H. The Napping Behaviour of Australian University Students. Plos One 2014;9:e113666.

23. Brooks A, Lack L. A Brief afternoon nap following nocturnal sleep restriction: which nap duration is most recuperative? Sleep 2006;29:831-40.

24. Anatsui TC, Adekanye EA. Television and academic performance of Nigerian youths: implications for national development. JE SD 2014;5:58-66.

25. Kibona L, Mgaya G. Smartphones' effects on academic performance of higher learning students. J MEST 2015;2:77784.

26. Barkley J, Lepp A. Cellular telephone use is associated with greater sedentary behavior independent of leisure-time physical activity. Int J Behav Nutr Phys Act 2013;10:79.

27. Petrov ME, Lichstein KL, Baldwin CM. Prevalence of sleep disorders by sex and ethnicity among older adolescents and emerging adults: Relations to daytime functioning, working memory and mental health. J Adolesc 2014;37:587-97.

28. Tanjung MF, Sekartini R. Masalah tidur pada anak. Sari Pediatri 2004;6:138-42. 